\title{
Microwave Assisted Synthesis of Novel Six-Membered 4-C, 4-O and 4-S Lactams Derivatives: Characterization and in vitro Biological Evaluation of Cytotoxicity and Anticoagulant Activity
}

\author{
Nicolás E. Núñez-Navarro, ${ }^{a}$ Gerardine F. Segovia ${ }^{a}$ Renato A. Burgos, ${ }^{b}$ Carlos $F$. \\ Lagos, ${ }^{c, d}$ Nataly Fuentes-Ibacache, ${ }^{c}$ Mario A. Faúndez ${ }^{b}$ and Flavia C. Zacconi ${ }^{*, a, e}$ \\ ${ }^{a}$ Departamento de Química Orgánica and ${ }^{b}$ Departamento de Farmacia, Facultad de Química, \\ Pontificia Universidad Católica de Chile, Avda. Vicuña Mackenna 4860, Macul, Santiago, Chile \\ 'Departamento de Endocrinología, Escuela de Medicina, Pontificia Universidad Católica de Chile, \\ Lira 85, Piso 5, Santiago, Chile \\ ${ }^{d}$ Facultad de Ciencia, Universidad San Sebastián, campus Los Leones, Lota 2465, \\ Providencia 7510157, Santiago, Chile \\ ${ }^{e}$ Centro de Investigación en Nanotecnología y Materiales Avanzados, CIEN-UC, \\ Pontificia Universidad Católica de Chile, Santiago, Chile
}

\begin{abstract}
A series of six-membered lactam derivatives containing $\mathrm{C}, \mathrm{O}$ and $\mathrm{S}$ atoms in position 4 were synthesized using microwave methodology through coupling reactions. The novel compounds were synthesized following two step reaction to yield fifteen derivatives. The final derivative $\mathrm{N}$-(4-(3oxotiomorpholin)phenyl) hexanamide was selectively toxic to the HCT-116 cell line over the HeLa cancerous and HEK-293 human non-malignant control cells with low inhibition Factor Xa (FXa) activity. The new products were characterized by spectral data including ${ }^{1} \mathrm{H}$ and ${ }^{13} \mathrm{C}$ nuclear magnetic resonance (NMR), infrared (IR) and high-resolution mass spectrometry (HRMS). Cytotoxicity of products on HCT-116, HeLa, HEK-293 cell lines and FXa activity assays are also reported.
\end{abstract}

Keywords: lactam derivatives, microwave, coupling reactions, cytotoxic activity, FXa activity

\section{Introduction}

According to statistics from the World Health Organization (WHO), ${ }^{1}$ the mortality rate associated with age-standardized cancer was 115.3 per 100,000 inhabitants in 2012. The analysis reported by the Department of Health Statistics and Information (DEIS), which is a department within the Chilean Health Ministry (MINSAL), reported that colon cancer was the cause of 1,410 deaths. This finding corresponds to a mortality rate of 8.2 per 1,000 people in 2012. ${ }^{2}$ This epidemiologic data supports the pressing need for on-going research to find novel compounds for the treatment of colon cancer.

Indeed, existing data from basic cancer research shows that the haemostatic components and the cancer biology are interlinked in multiple ways. ${ }^{3}$ Nonetheless, it is noteworthy that while a group of cancer cells is capable of activating

*e-mail: fzacconi@uc.cl the clotting system, haemostatic factors play a role in tumor progression. ${ }^{4}$ Moreover, current antineoplastic drugs are useless due to their high toxicity, side effects and low selectivity. Thus, novel scaffolds for the development of antineoplastic drugs has become a rapidly growing field of scientific interest, and highlight the development of small molecules with activity involving lactam moieties. ${ }^{5}$

Usually, reported protocols for synthesizing these interesting kinds of structures require multiple-step synthesis, long reaction times and high temperatures which ultimately results in low yields of the desired products. ${ }^{6}$

In this context, our research group is focused on the synthesis of new 4-C, 4-O and 4-S lactams with an aromatic amide substituent by means of using microwave assisted methodologies in order to diminish reaction time and increase the yield of the product. In this research, a modified Ullmann type reaction, using microwave approach and peptide coupling methods ${ }^{7}$ was performed to provide a new group of interesting compounds with enhanced 
selective cytotoxic activity for neoplastic cells HCT-116 (human colon cancer).

The chemical structure of these newly synthesized molecules has a similar main core of Factor Xa (FXa) commercially available oral anticoagulant drug known as Rivaroxaban $\left(\right.$ Xarelto $\left.^{\circledR}\right)$ (Figure 1). ${ }^{8}$ This new oral inhibitor is specific for FXa, which has a critical role in the human coagulation cascade due to its central position, which links the extrinsic and intrinsic pathways to the final common coagulation pathway. ${ }^{9}$ Furthermore, it has been reported that FXa inhibitors have effect over migration of breast, lung and colon cancer cells. ${ }^{10}$<smiles>O=C(NC[C@H]1CN(c2ccc(N3CCOCC3=O)cc2)C(=O)O1)c1ccc(Cl)s1</smiles><smiles>[X]CCCN1CCCCC1=O</smiles>

6-8, 9a-11d

Figure 1. Rivaroxaban (1) chemical structure and synthesized lactam derivatives (6-8, 9a-11d) $(X=C, O, S ; n=4-7)$.

In the present work we report on a new group of 4-C, 4-O and 4-S lactam derivatives with peptide aromatic moieties analogous to the commercial FXa inhibitor (Figure 1) that is synthesized through coupling reaction by using microwave assisted methodology, cytotoxic activity on cancerous HCT-116 and HeLa (human epithelial cervix carcinoma) cell lines and noncancerous HEK-293 (human embryonic kidney) cell line measured by a tetrazolium salt reduction assay (MTT-assay), and FXa inhibition assay of synthesized compounds.

\section{Experimental}

\section{Synthesis procedures}

We initially investigated the microwave-promoted Ullmann type coupling reaction of 4-C, 4-O and 4-S lactams ( 1.2 equiv.) using $\mathrm{CuI}(0.05$ equiv.) as catalyst with 4-iodoaniline (or 4-bromoaniline) (1 equiv.) in dry toluene $(\mathrm{PhMe})$ in the presence of $N, N^{\prime}$-dimethlyethylenediamine (DMEN) (0.1 equiv.) as ligand, and $\mathrm{K}_{3} \mathrm{PO}_{4}$ ( 2 equiv.) as the base and irradiated with power (4-6 bar, 850 watts) at $110{ }^{\circ} \mathrm{C}$ for 2 hours $(2 \mathrm{~h})$. This new microwave (MW) assisted approach decreased the reaction time from 16-72 to $2 \mathrm{~h}$ to produce the precursors of interest 6-8. The second step of the synthesis was carried out through a modified peptide coupling reaction at room temperature between lactams 6-8, which have different heteroatoms at position 4 , and fatty acids with varying chain lengths $(n=4-7)$ in order to modify the lipophilicity characteristics of the novel compounds (Scheme 1).

This second reaction was carried out using the precursors with fatty acids in peptide coupling conditions: a mixture of 1-hydroxybenzotriazole (HOBt) (2 equiv.) and $N$-ethyl- $N$ '-(3-dimethylaminopropyl)carbodiimide hydrochloride (EDAC.HCl) (2 equiv.), as carboxylic acid activating agents, and arylamines (1 equiv.) were weighed and transferred into a dried reaction tube. The tube was evacuated and back filled with dry $\mathrm{N}_{2}$. Fatty acids (1.2 equiv.), $N, N$-diisopropylethylamine (2.5 equiv.), pyridine (Py) (0.01 equiv.) and dry dichlorometane (DCM) $(5 \mathrm{~mL})$ were injected into the tube and stirred at room temperature (r.t.) for $6 \mathrm{~h}$. After this time, all compounds were isolated using flash chromatography techniques (for<smiles>[X]CC(=O)NCC</smiles>

2: $X=C$

3: $X=0$

4: $X=S$<smiles>[X]CCCN(C(=O)CC)c1ccc(N)cc1</smiles>

6-8<smiles>O=C(Nc1ccc(N2C[X]CC2)cc1)C(=O)N1CCCCC1</smiles>

9-11 9a: $X=C n=4(95 \%)$

9b: $X=C n=5(98 \%)$

9c: $X=C n=6(97 \%)$

9d: $X=C n=7(96 \%)$

10a: $X=O n=4(95 \%)$

10b: $X=O n=5(97 \%)$

10c: $X=O n=6(97 \%)$

10d: $X=O n=7(98 \%)$

11a: $X=S n=4(95 \%)$

11b: $X=S n=5(95 \%)$

11c: $X=S n=6(98 \%)$

11d: $X=S n=7(95 \%)$

Scheme 1. (a) CuI (0.05 equiv.), $\mathrm{K}_{3} \mathrm{PO}_{4}$ (2 equiv.), DMEN (0.1 equiv.), $\mathrm{PhMe}, \mathrm{MW}(4-6 \mathrm{bar}, 850 \mathrm{~W}), 110{ }^{\circ} \mathrm{C}, 2 \mathrm{~h}(60-75 \%)$; $(\mathrm{b}) \mathrm{HOOC}\left(\mathrm{CH}_{2}\right)_{\mathrm{n}} \mathrm{CH} \mathrm{H}_{3}(\mathrm{n}=4-7)$ (1.2 equiv.), HOBt (2 equiv.), EDAC.HCl (2 equiv.), DiPEA (2.5 equiv.), Py (0.01 equiv.), r.t., 6 h (95-98\%). 
complete methodology description see Supplementary Information).

\section{Cell culture and in vitro cytotoxicity assays}

HCT-116 (human colorectal carcinoma, ATCC number CCL- 247), HeLa (human epithelial cervix carcinoma, ATCC number CCL-2) and HEK-293 (human embryonic kidney, ATCC number CRL-1573) cells were cultured in an RPMI 1640 medium supplemented with 5\% fetal bovine serum (FBS) in humidified air with $5 \% \mathrm{CO}_{2}$ at $37^{\circ} \mathrm{C}$. Cytotoxicity assays were performed using the MTT reduction method. ${ }^{11}$ Ten thousand cells were seeded in $0.2 \mathrm{~mL}$ of culture medium using a flat-bottom 96-well plate. All synthesized compounds (6-11), Rivaroxaban (1) and Etoposide (positive control) were assayed at concentrations of $50 \mathrm{nM}, 500 \mathrm{nM}, 5 \mu \mathrm{M}$ and $50 \mu \mathrm{M}$ on HCT-116, HeLa and HEK-293cells lines. MTT was added at a final concentration of $0.5 \mathrm{mg} \mathrm{mL}^{-1}$, incubated for $4 \mathrm{~h}$, and then solubilized with $10 \%$ sodium dodecyl sulfate $/ 0.1 \mathrm{mM}$ $\mathrm{HCl}$ and incubated overnight. Formazan production was measured at $570 \mathrm{~nm}$ in a multiwell reader (Synergy Neo, Biotek Inc.).

\section{Results and Discussion}

The first synthesis step using this new microwave (MW) assisted approach decreased the reaction time from 16-72 to $2 \mathrm{~h}$ to produce the precursors of interest 6-8. This first step was performed in 2 hours to produce derivatives 6-8 in good yields (60-75\%) of purified products.

Moreover, the addition of pyridine in catalytic amounts increased the yield of the peptide coupling products by $10-15 \%$. Derivatives 9-11 were obtained in excellent yields (95-98\%) of isolated compounds by using the peptide coupling variation methodology performed at room temperature. In order to confirm the corresponding structures, all novel small molecules were fully characterized by available spectroscopic techniques. For more information see Supplementary information (SI).

With the aim to evaluate the cytotoxicity effect all synthesized compounds (6-11), Rivaroxaban (1) and Etoposide (positive control) were assayed using MTT methodology at concentrations of $50 \mathrm{nM}, 500 \mathrm{nM}, 5 \mu \mathrm{M}$ and $50 \mu \mathrm{M}$ on HCT-116, HeLa and HEK-293cells lines.

Figure 2 shows the dose-response curve for compound 11a ( $N$-(4-(3-oxotiomorpholin)phenyl) hexanamide), Etoposide (positive control) and Rivaroxaban (1) in HCT-116 cells. The treatment with compound 11a significantly reduced (over the $50 \%$ of reduction in the cell grown) the survival of HCT-116 cells with the corresponding $\mathrm{IC}_{50}$ value of
$1.89 \mu \mathrm{M}$. Compound 11a had IC50 value on the same order of magnitude as the control drug. Additionally, there were no significant differences in cell viability between compounds 6-10d, 11b-11d, and the cell control group. For more details see Table S1, Supplementary Information (SI). Although, all tested compounds did not show cytotoxic effects on cancerous HeLa and noncancerous HEK-293 cell lines, these results showed us the specificity of compound 11a on HCT-116. Compound 11a was the most active of the synthesized groups of novel molecules and it exhibited a single-digit micromolar $\mathrm{IC}_{50}$ value, which accords with the National Cancer Institute (NCI) protocols where compounds that exhibit $\mathrm{IC}_{50}$ values $<10$ or $15 \mu \mathrm{M}$ are considered active. ${ }^{12}$

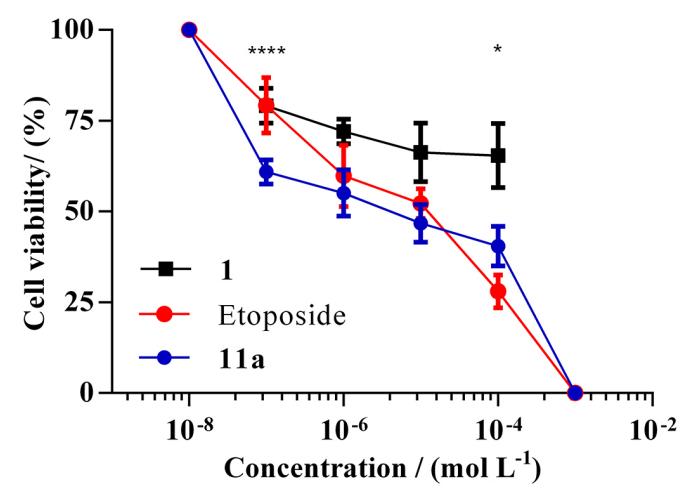

Figure 2. Cytotoxicity effect of compound 11a, Etoposide and Rivaroxaban (1) in HCT-116 cells. Tested concentrations of $50 \mathrm{nM}$, $500 \mathrm{nM}, 5 \mu \mathrm{M}$ and $50 \mu \mathrm{M}$. Dose-response curves of: compound 11a, $\mathrm{IC}_{50}: 1.89 \mu \mathrm{M}, \mathrm{r}^{2}: 0.83$; Etoposide, $\mathrm{IC}_{50}: 2.80 \mu \mathrm{M}, \mathrm{r}^{2}: 0.93$; and - Rivaroxaban (1). The values are presented as mean \pm SD of at least triplicates. $*: \mathrm{p}<0.1$ and $* * * *: \mathrm{p}<0.0001$ for 11a in comparison with Etoposide control by two-way ANOVA test.

Due to the relationship between cancer pathology and coagulation consequences in vitro FXa inhibition assays were performed. Newly synthesized derivatives have been shown to display very low (10-25\%) or to have no activity as a direct FXa inhibitors (for more details see SI, Table S2). As shown in Figure 3, compound 11a produced a low 16\% of FXa inhibition activity in contrast to the commercially available FXa inhibitor (1) which displayed a 95\% FXa inhibitory activity.

In the first step, structurally related compounds were synthesized from lactams with different atom in position 4 , and the second steps considered the coupling reaction using distinct fatty acids. Interestingly, all novel synthesized small molecules were obtained in order to evaluate the possible correlation between the lipophilicity of compounds (6-8, 9a-11d) and their cytotoxic effects. The lipophilicity was able to be estimated by using the $\log$ arithm form $(\log \mathrm{P})$ as the octanol-water partition coefficient (see SI, Table S3), and it is related with the membrane permeability. However, 


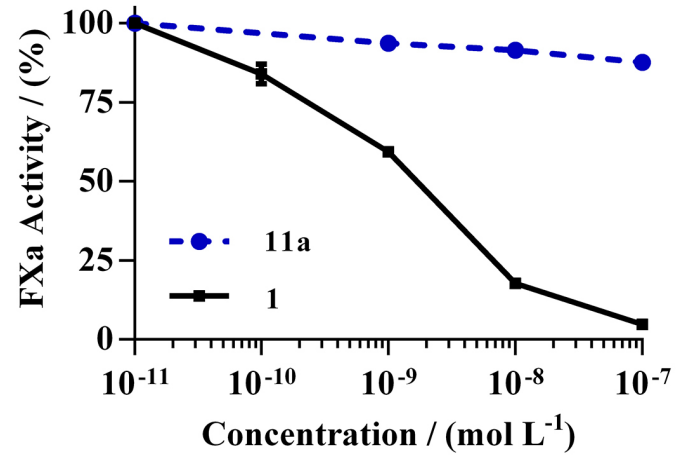

Figure 3. FXa activity of compound 11a and commercial FXa inhibitor (1).

no correlation was observed between the compound's cytotoxicity and its $\log \mathrm{P}$ values for the evaluated cell lines. Although of little significance, compounds with moderate or low lipophilicity ( $\log \mathrm{P}>3$ ) tend to exhibit the best antitumor activity. In our study, compound 11a has demonstrated itself to be selective cytotoxic for HCT-116 over the HeLa cell line with an estimated low lipophilicity $(\log \mathrm{P}=2.53)$. The lack of correlation between lipophilicity and antitumor activity suggests that cell permeability is not critical for the cytotoxic effect. Moreover, compound 11a display no relevant inhibitory effect on FXa (Figure 3).

This interesting results turns 11a into a leading potential compound for the development of new oral anti-cancer drugs that exhibit low lipophilicity, and that also do not affect the coagulation cascade factor Xa. Furthermore, it is noteworthy that this present first-time synthetic and biological approach has resulted in the development of a simple, fast and efficient synthetic methodology for developing these kinds of interestingly novel compounds.

\section{Conclusions}

In conclusion, we have described a simple, fast and efficient synthetic route to obtain a new group of 4-C, 4-O and 4-S lactams with aromatic peptide moieties that produces excellent yields of isolated products. In addition, novel compound 11a was selectively toxic to the HCT-116 cell line over the HeLa cancerous and HEK-293 human non-malignant control cells, which showed low inhibition FXa activity. Thus, these preliminary results showed that compound 11a is a promising leader for the development of new antitumor drugs that do not inhibit FXa activity.

\section{Supplementary Information}

Complete synthesis methodologies, cell culture, cytotoxicity assay, inhibition FXa assay, and NMR spectra data of compounds 6-11 are available free of charge at http://jbcs.sbq.org.br, as PDF file.

\section{Acknowledgments}

This work was financially supported to F. Z. by the Fondecyt Iniciación No. 11130595 project. G. S. is grateful to Pontificia Universidad Católica de Chile for Beca VRIUC. F. Z. is thankful to Prof R. Rojas for providing access to the microwave reactor. C. F. L. acknowledges ChemAxon Ltd. for academic license of their products.

\section{References}

1. World Health Organization, available at http://apps.who.int/ gho/data/node.main.A864, accessed in September 2016.

2. DEIS, Ministerio de Salud, Gobierno de Chile, available at http://www.deis.cl/defunciones-y-mortalidad-por-causas/, accessed in August 2016.

3. Rickles, F. R.; Edwards, R. L.; Blood 1983, 62, 14; Rickles, F.; Hancock, W.; Semin. Thromb. Hemostasis 1988, 14, 126; Shakhlamov, V. A.; Bitner, E. G.; Bull. Exp. Biol. Med. 1992, 114, 81; Shi, K.; Queiroz, K. C.; Roelofs, J. J.; van Noesel, C. J.; Spek, C. A.; J. Pathol. 2014, 234, 398.

4. Cohen, J. R.; Grella, L.; Citron, M.; Cancer 1992, 70, 1993; Falanga, A.; Marchetti, M.; Vignoli, A.; J. Thromb. Haemostasis 2013, 11, 223; Mitrugno, A.; Tormoen, G. W.; Kuhn, P.; McCarty, O. J. J.; Blood Rev. 2016, 30, 11; Hisada, Y.; Geddings, J. E.; Ay, C.; Mackman, N.; J. Thromb. Haemostasis 2015, 13, 1372; Hisada, Y.; Alexander, W.; Kasthuri, R.; Voorhees, P.; Mobarrez, F.; Taylor, A.; McNamara, C.; Wallen, H.; Witkowski, M.; Key, N. S.; Rauch, U.; Mackman, N.; Thromb. Res. 2016, 139, 90.

5. Giannini, G.; Battistuzzi, G.; Vignola, D.; Vesci, L.; Taddei, M.; European pat. WO 2014122222 A1 2014; Soares, J.; Raimundo, L.; Pereira, N. A.; dos Santos, D. J.; Pérez, M.; Queiroz, G.; Leao, M.; Santos, M. M.; Saraiva, L.; Pharmacol. Res. 2015, 95, 42; Saha, S.; Welsch, D.; DeCrescenzo, G.; Roix, J. J.; US pat. WO/2015/095840 2015.

6. Klapars, A.; Huang, X.; Buchwald, S. L.; J. Am. Chem. Soc. 2002, 124, 7421; Cristau, H. J.; Cellier, P. P.; Spindler, J. F.; Taillefer, M.; Chem. Eur. J. 2004, 10, 5607; Mali, A. C.; Deshmukh, D. G.; Joshi, D. R.; Lad, H. D.; Patel, P. I.; Medhane, V. J.; Mathad, V. T.; Sustainable Chem. Processes 2015, 3:11.

7. Han, S. Y.; Kim, Y. A.; Tetrahedron 2004, 60, 2447; Montalbetti, C. A. G. N.; Falque, V.; Tetrahedron 2005, 61, 10827; Valeur, E.; Bradley, M.; Chem. Soc. Rev. 2009, 38, 606; Revanna, R. H.; Panchangam, R. K.; Bhanu, U.; Doddavenkatanna, S.; J. Braz. Chem. Soc. 2016, 27, 1157.

8. Roehrig, S.; Straub, A.; Pohlmann, J.; Lampe, T.; Pernerstorfer, J.; Schlemmer, K. H.; Reinemer, P.; Perzborn, E.; J. Med. Chem. 2005, 48, 5900 .

9. Ruf, W.; Dorfleutner, A.; Riewald, M.; J. Thromb. Haemostasis 2013, 1, 1495; Pavlova, A.; Preisler, B.; Driesen, J.; de 
Moerloose, P.; Zieger, B.; Hütker, S.; Dengler, K.; Harbrecht, U.; Oldenburg, J.; Haemophilia 2015, 21, 386.

10. Sampson, M. T.; Kakkar, A. K.; Biochem. Soc. Trans. 2002, 30, 201; Borensztajn, K.; Peppelenbosch, M. P.; Spek, C. A.; Thromb. Res. 2010, 125, e323; Sierko, E.; Wojtukiewicz, M. Z.; Zimnoch, L.; Kisiel, W.; Thromb. Haemostasis 2010, 103, 198; Sierko, E.; Wojtukiewicz, M. Z.; Zimnoch, L.; Tokajuk, P.; Ostrowska-Cichocka, K.; Kisiel, W.; Thromb. Res. 2012, 129, e112.
11. Mosmann, T.; J. Immunol. Methods 1983, 65, 55; Berridge, M. V.; Herst, P. M.; Tan, A. S.; Biotechnol. Annu. Rev. 2005, 11, 127.

12. Chazin, E. L.; Sanches, P. S.; Lindgren, E. B.; Vellasco Jr., W. T.; Pinto, L. C.; Burbano, R. M. R.; Yoneda, J. D.; Leal, K. Z.; Gomes, C. R. B.; Wardell, J. L.; Wardell, S. M. S. V.; Montenegro, R. C.; Vasconcelos, T. R. A.; Molecules 2015, 20, 1968. 